\title{
La escoleta y la capilla de músíca de la catedral de Guadalajara (1690-1750)
}

\author{
José Gabino Castillo Flores \\ Universidad Autónoma de Coahuila \\ josegabinocastillo@hotmail.com
}

La obra de Cristóbal Durán se Reseña del libro de Cristóbal M. Durán Moncada, La escoleta y la capilla de música de la catedral de Guadalajara timos años se ha abocado a escla(1690-1750). Guadalajara, Universidad recer la historia de las catedrales y su mundo sonoro. El autor invita de Guadalajara, 2014. a comprender, usando el ejemplo $215 \mathrm{pp}$. de Guadalajara, que las catedrales eran importantes centros de formación de músicos y de desarrollo musical enclavados en las principales ciudades del virreinato. A lo largo de la obra el autor nos lleva por la historia de la ciudad y la catedral para después, puertas adentro de ésta, mostrarnos el funcionamiento de su escoleta y capilla de música, dos entidades que contribuían al esplendor del culto divino.

En su primer capítulo, "La ciudad y la catedral", el autor analiza el importante papel que la catedral tuvo en el entramado urbano de Guadalajara. Para ello hace un recorrido histórico que relata la fundación y constitución de la ciudad, enclave que sirvió de base para la colonización y el poblamiento de las tierras del septentrión novohispano. Asimismo, el autor estudia la ciudad como un escenario donde se desenvuelve la vida cotidiana y la religiosidad, pero también como un lugar que, en su distribución y complejidad, refleja la sociedad de su época, una en la que las jerarquías tienen un papel de gran relevancia. Muestra de ello son las procesiones y fiestas en las que desfila no sólo el santo en sus andas sino también una sociedad multiétnica donde cada cual ocupa el lugar que le corresponde. De esta forma, la catedral, si nos atenemos a la distribución espacial, tiene un lugar primordial en la traza urbana, como también su 
clero en la sociedad. No es fortuito, por tanto, que el papel del estamento religioso en las fiestas, pensemos por ejemplo en la de Corpus, tenga un papel protagónico.

La ciudad es, pues, vista en el texto de Cristóbal Durán, un escenario de cal y canto, pero también de prácticas socioculturales. Es ahí donde hay que ubicar la catedral. Por ello es comprensible que el autor resalte la consagración de la catedral como uno de los momentos de verdadero triunfo para Guadalajara. Al ser una de las primeras en haber sido consagradas (en 1716, sólo después de la de Puebla que lo había sido en 1649), la ciudad exaltó su importancia en el tejido urbano y eclesiástico del virreinato.

Tras mostrar un poco de la historia, el autor nos lleva puertas adentro de la iglesia matriz para estudiar dos importantes entidades: la escoleta y la capilla de música. Las aborda por separado, dedicando a cada una un apartado del libro. El capítulo dos lleva por título precisamente "La escoleta de música". En él Cristóbal Durán señala el importante papel que la escoleta, un tema poco tratado por la historiografía, tuvo para la formación de músicos en las diversas diócesis. Considerada en el Tercer Concilio Provincial Mexicano, la escoleta fue, por lo general, una clase de música, solfeo y canto que existió en algunos conventos, catedrales, parroquias, seminarios y colegios en los siglos virreinales. Ya para el siglo XVIII algunas como la de Guadalajara, se convirtieron en una escuela pública de música a la que podían acudir no sólo los miembros de la capilla de la catedral, sino toda aquella persona que quisiera aplicarse a este oficio. Dado que la catedral de Guadalajara no tuvo un colegio de infantes sino hasta el siglo XIX, la escoleta cumplió un papel relevante como espacio para la formación de músicos. Asimismo, debido a que comúnmente el maestro de capilla lo era también de la escoleta, posibilitó el reclutamiento de los mejores ejecutantes para el servicio del culto catedralicio.

La escoleta de Guadalajara se consolidó a finales del siglo XVII de la mano de Martín Casillas, quien también había tenido a su cargo la de Valladolid. En 1691, a un año de la llegada de Casillas a Guadalajara, la escoleta empezó a aparecer con este nombre en la documentación, pues antes era conocida únicamente como la lección de música y solfa. El impulso dado por este personaje redundó también en la capilla de música, pues se nutrió de buenos músicos a los que incluso, por primera vez, se les empezó a contratar por medio de concursos de oposición. Aquella bonanza era general, precisamente durante los primeros treinta años del siglo XVIII, la catedral se consolidó en su ciudad y obispado, y muestra tangible de ello fue la culminación de la fábrica de sus torres y la construcción de los órganos de grandes dimensiones que se estrenaron en 1730 para magnificencia del culto divino. 
Por desgracia, como bien apunta el autor, los buenos tiempos de la escoleta, entre 1690 y 1730, no fueron eternos. Varias circunstancias causaron su estancamiento en las décadas de 1730 a 1750. La primera de ellas fue la muerte de Martín Casillas, ocurrida en 1719; tras su muerte la escoleta recayó en su hijo Bernardo Casillas, quien, no obstante, estuvo lejos de poseer las habilidades de su padre. A lo anterior se sumaron las consecuencias del periodo de pestes que afectó a la mayor parte del territorio virreinal entre 1737 y 1739. Debido a ello, la década siguiente fue un periodo en el que las rentas catedralicias se vieron mermadas, lo que impactó en la no contratación de músicos para la catedral. Las cosas no mejorarían sino hasta la segunda mitad del siglo xVIII, luego de la contratación de Francisco Rueda como maestro de capilla y de escoleta en 1750.

Como se muestra en el capítulo tres de la obra, "La capilla de música", el desarrollo de dicha agrupación corrió una suerte similar a la escoleta. Hasta 1620 la capilla estaba apenas en formación y fue difícil que su estado mejorara luego de la creación del obispado de Durango, que minó parte de las rentas de la catedral. Por esos años seguía predominando en Guadalajara el canto llano, pues contaba con apenas unos diez músicos y pocos instrumentos en la capilla. La situación de ésta mejoró en la segunda mitad del siglo, pues pudo contratar a mayor cantidad de cantores y ministriles, e incluso creó el oficio de ayudante del sochantre. Para 1690 la capilla se reforzó con la llegada del ya mencionado Martín Casillas, quien ocupó el cargo de maestro en ésta y en la escoleta. Sin embargo, el esplendor de la capilla tuvo también sus altibajos luego de la muerte de dicho personaje y, en particular, tras los efectos de la epidemia de 1737, y mejoró nuevamente, al igual que la escoleta, después de 1750.

Sabemos que las capillas de música tuvieron una gran importancia para las catedrales y Cristóbal Durán ayuda a comprender mejor su papel, así como su composición. El autor explica en qué consistía cada uno de los cargos de quienes la integraban: seises, cantores, ministriles, capellanes de coro, etcétera. Además se reseñan los tipos de canto, por ejemplo llano y figurado, que se desarrollaban en la liturgia catedralicia. En medio de este entramado llama la atención la presencia de músicos indios, algunos de los cuales ingresaron a la capilla de música por medio de exámenes de oposición, lo que habla no sólo de sus habilidades musicales sino de su integración en la sociedad. Asimismo, el autor muestra cómo el mundo sonoro de las catedrales dependió, además, de la evolución histórica de los instrumentos dentro de la catedral; durante los siglos XVI y XVII, por ejemplo, predominaron los aerófonos, mientras que a fines del XVII y primeras décadas del xviII las capillas de música dieron la bienvenida a los instrumentos de cuerda, violines, violas, arpas, entre otros, que dieron 
un vuelco a la composición estilística de las piezas. A lo anterior hay que sumar el mencionado órgano de tribuna que se acabó de construir en la catedral en 1730. Su manufactura había llevado a una ampliación de las tribunas del coro, lo que ocasionó una renovación no sólo espacial sino sonora del interior de la catedral. Esto es una muestra de la importancia del ámbito sonoro en el ritual catedralicio, algo que Cristóbal Durán deja bien claro a lo largo de su trabajo.

La obra aquí reseñada se suma de buena forma a la historiografía reciente que analiza el papel de la música y de los músicos en las catedrales. Basta acercarse a ella para comprender que no es posible entender la liturgia catedralicia sin el aspecto sonoro. Se trata de una música al servicio de la catedral y del culto divino, un medio de adoración a Dios. Las catedrales buscaron tener siempre una importante capilla formada por músicos diestros, pues la correcta ejecución del culto y su solemnidad reflejaban también la importancia del recinto y de su clero. El texto es una muestra de este proceso por el cual la catedral de Guadalajara buscó ganarse un lugar en el mundo de las catedrales del virreinato novohispano. 